\title{
New Alternatives for Atherosclerosis Treatment Based on Immunomodulation
}

\author{
Livan Delgado Roche and Danay Alfonso Hernández \\ Center for Research and Biological Evaluations, Institute of Pharmacy and Food Sciences, University of Havana, \\ 13600 Havana, Cuba \\ Correspondence should be addressed to Livan Delgado Roche, ldelgado@ifal.uh.cu
}

Received 12 July 2012; Accepted 13 August 2012

Academic Editors: A. Mugge and A. Paolicchi

Copyright ( $\odot 2012$ L. Delgado Roche and D. Alfonso Hernández. This is an open access article distributed under the Creative Commons Attribution License, which permits unrestricted use, distribution, and reproduction in any medium, provided the original work is properly cited.

\begin{abstract}
Atherosclerosis and its derived cardiovascular diseases are a leading cause of death in the western world. The treatment of atherosclerosis is currently based on lipid lowering in combination with anti-inflammatory therapies that slow the progression of atherosclerosis. Still, these therapies are not able to fully inhibit the formation or progression of atherosclerotic lesions. Ever since it was first demonstrated that the immunological system plays an important role during atherogenesis, various different immunotherapeutic approaches have been evaluated with promising results. Notwithstanding that, one of the difficulties in developing effective vaccination strategies for atherosclerosis is the selection of a specific target. So far, vaccination strategies have been based on the targeting of lipid antigens, inflammation-derived antigens, and cell-based vaccination strategies. More recently, strategies aimed at blocking the retention of low-density lipoproteins by arterial proteoglycans have emerged as a promising tool. In the study at hand we reviewed the most relevant advances on atherosclerosis immunotherapy cited in the PubMed database from 1980 to 2012 .
\end{abstract}

\section{Introduction}

Atherosclerosis is a chronic arterial disease that causes myocardial and cerebral infarctions, leading causes of death in the western world. The incidence of atherosclerosis-based diseases remains high in developed societies, and it is rapidly increasing in many developing countries alongside economic development [1].

Several hypotheses have been accepted since Steinberg and coworkers enunciated the oxidative hypothesis in 1989 $[2,3]$, in which they postulated that reactive oxygen species (ROS) induced low-density lipoprotein (LDL) oxidation is closely associated with atherosclerosis development. Some years later, Williams and Tabas suggested that LDL retention is a primary and key step in atherogenesis $[4,5]$. The retained LDL is more susceptible to oxidation, resulting in atherogenic forms conversion. On the other hand, the active role of the immunological system during atherogenic progress was described by Hansson [6], while in 1999, Ross postulated the response to injury or inflammatory hypothesis [7].
The treatment of atherosclerosis is currently based on lipid lowering in combination with anti-inflammatory therapies that slow the progression of atherosclerosis. Still, these therapies are not able to fully inhibit the formation or progression of atherosclerotic lesions. The maximum efficacy of these strategies in different clinical trials has been measured at only $30 \%$ to $40 \%$ [8].

After it was demonstrated that the immunological system plays an important role during atherogenesis, anti-inflammatory and immunomodulatory strategies have become the preferred emerging treatments to target the root causes of the disease. Additional immunotherapeutic approaches have been recently evaluated with promising results [9-15].

The purpose of these therapies has been to interfere with lipoprotein metabolism [16], but also to modulate specific immune responses that play key roles in the development of the inflammatory process involved in the pathogenesis of the disease $[17,18]$. In contrast, therapies based on vessel wall targets, especially those directed at preventing the 
TABLE 1: Experimental therapies based on immunomodulation of atherosclerosis.

\begin{tabular}{|c|c|c|}
\hline \multirow[t]{10}{*}{$\begin{array}{l}\text { Immunotherapeutic } \\
\text { approaches }\end{array}$} & Lipid-based vaccination strategies & Reference \\
\hline & $\begin{array}{l}\text { Peptide-based vaccine (B-cell-derived CETP } \\
\text { epitope combined with a T-helper-cell epitope) }\end{array}$ & $\begin{array}{l}\text { Rittershaus et al., } \\
\quad 2000[19]\end{array}$ \\
\hline & $\begin{array}{l}\text { Chimeric peptide (T-helper-cell epitope of HSP65 } \\
\text { and a B-cell epitope of human CETP) }\end{array}$ & $\begin{array}{l}\text { Gaofu et al., } 2005 \\
{[20]}\end{array}$ \\
\hline & \multicolumn{2}{|l|}{$\begin{array}{l}\text { Vaccination strategies based on epitopes of oxidized } \\
\text { LDL }\end{array}$} \\
\hline & $\begin{array}{l}\text { 2D03-IgG, recombinant human antibodies } \\
\text { against MDA-ApoB100 }\end{array}$ & $\begin{array}{c}\text { Schiopu et al., } 2007 \\
{[21]}\end{array}$ \\
\hline & $\begin{array}{l}\text { Xenogeneic polyclonal antibodies against } \\
\text { electronegative LDL }\end{array}$ & $\begin{array}{l}\text { Grosso et al., } 2008 \\
{[10]}\end{array}$ \\
\hline & OxLDL-pulsed mature dendritic cells & $\begin{array}{l}\text { Habets et al., } 2010 \\
{[12]}\end{array}$ \\
\hline & $\begin{array}{l}\text { Peptide of apoB-100 (p210) fused to the B } \\
\text { subunit of cholera toxin }\end{array}$ & $\begin{array}{l}\text { Klingenberg et al., } \\
2010[22]\end{array}$ \\
\hline & Tolerogenic dendritic cells & $\begin{array}{l}\text { Hermansson et al., } \\
2011[14]\end{array}$ \\
\hline & Vaccination with MDA-modified fibronectin & $\begin{array}{c}\text { Dunér et al., } 2011 \\
{[13]}\end{array}$ \\
\hline & \multicolumn{2}{|l|}{ Heat shock proteins } \\
\hline & $\begin{array}{l}\text { Oral and nasal mucosal administration of } \\
\text { Mycobacterium HSP } 60 / 65\end{array}$ & $\begin{array}{l}\text { Maron et al., } 2002 \\
\text { [23], Van Puijvelde } \\
\text { et al., } 2007 \text { [24] }\end{array}$ \\
\hline & \multicolumn{2}{|l|}{ B-cells modulation } \\
\hline & $\begin{array}{l}\text { B cell depletion using a CD20-specific } \\
\text { monoclonal antibody }\end{array}$ & $\begin{array}{l}\text { Ait-Oufella et al., } \\
\quad 2010 \text { [11] }\end{array}$ \\
\hline & \multicolumn{2}{|l|}{ Therapies based on response-to-retention hypothesis } \\
\hline & Inhibition of LDL-biglycan binding by endostatin & $\begin{array}{l}\text { Zeng et al. } 2005 \\
\qquad[25]\end{array}$ \\
\hline & $\begin{array}{l}\text { Inhibition of LDL-GAGs binding by chP3R99 } \\
\text { monoclonal antibody }\end{array}$ & $\begin{array}{l}\text { Soto et al., } 2012 \\
{[15]}\end{array}$ \\
\hline
\end{tabular}

CETP: cholesteryl ester transfer protein; HSP: heat shock protein; MDA: malondialdehyde; LDL: low-density lipoprotein; OxLDL: oxidized low-density lipoprotein; GAGs: glycosaminoglycans.

subendothelial retention of atherogenic lipoproteins, have been much less explored. Recently, however, our group demonstrated the antiatherogenic properties of an antibody that binds extracellular glycosaminoglycans (GAGs) [15].

The purpose here is to examine the state-of-the-art and recent advances in atherosclerosis immunotherapy, focusing on more recent and relevant advances in this field (see Table $1)$.

\section{Lipid-Based Vaccination Strategies}

Since lipids are key biomolecules in atherosclerosis, several vaccination strategies have targeted different proteins considered central in lipid metabolism. Over the past decade interest has turned to modulation of cholesteryl ester transfer protein (CETP) activity.

Rittershaus et al. developed a strategy in which they immunized rabbits with a peptide-based vaccine, containing a B-cell derived CETP epitope in combination with a T-helper-cell epitope (to overcome B-cell nonresponsiveness towards self-antigens) as a chaperone molecule. This approach resulted in the inhibition of atherosclerotic lesion formation, associated with increased CETP antibodies, decreased CETP activity, and modified lipoprotein profiles [19]. A similar approach was conducted five years later, where rabbits were vaccinated by repeated subcutaneous injections using rHSP65-CETPC (chimeric peptide containing a helper T-cell epitope of HSP65 and a B-cell epitope of human CETP) in alum adjuvant. This vaccination strategy increased CETP antibodies, but also HSP65 antibodies. Additionally, a more atheroprotective lipoprotein profile and attenuated atherosclerotic lesion formation were observed [20]. Intramuscular DNA vaccination targeting CETP has been shown to be similarly effective as a peptide-based vaccination [26]. A new factor was introduced whereby human intestinal trefoil factor (TFF3) was employed as a molecular vehicle for the CETP B-cell epitope, which allows oral administration of the chimeric peptide [27]. 
Progress was observed in that repeated oral administration of the chimeric peptide ameliorated atherosclerotic lesion development via induction of CETP-specific IgG/IgA antibodies.

\section{Vaccination Strategies Based on Epitopes of Oxidized LDL}

The different epitopes of oxidized LDL (oxLDL) induce atherogenic immune responses. This is an effective tool for modulation of the immune response to oxLDL. Also, a number of studies have shown that immunization against oxLDL reduces atherosclerosis in several animal models [12, 28].

The uptake of modified LDL by dendritic cells (DCs) and the presentation of epitopes thereof may form an important step in the immunomodulatory effects of LDL. Due to their potent capacity to stimulate $\mathrm{T}$ cells, DCs are being investigated in vaccine and therapy approaches. Indeed, the transfer of oxLDL-pulsed mature DC has resulted in an $87 \%$ reduction in carotid artery lesion size, with a concurrent increase in plaque stability, whereas treatment using DC pulsed with the atherosclerosis-irrelevant antigen, ovalbumin, did not influence lesion size or stability. Furthermore, the vaccination procedure resulted in the induction of oxLDL-specific T cells with a reduced Th1 profile and an increase in oxLDL-specific IgG levels, which contributed to a reduction in foam cell formation [12].

Recently, Hermansson and coworkers have shown that interleukin 10 (IL-10) imposes a regulatory phenotype on DC and that such tolerogenic DC induce T-cell tolerance to ApoB100, blunt Th1 responses, and suppress autoimmune inflammation in hypercholesterolemic mice in an ApoB100specific manner. Treatment of disease-prone hypercholesterolemic mice with a single injection of tolerogenic DC led to significantly reduced atherosclerosis [14].

Moreover, immunization with a peptide of apoB-100 (p210) fused to the B subunit of cholera toxin (CTB), which binds to a ganglioside on mucosal epithelia for 12 weeks, caused a 35\% reduction in aortic lesion size in atherosclerosis-prone apoE-deficient mice [22]. The treatment also induced regulatory $\mathrm{T}$ cells while suppressing effector $\mathrm{T}$ cells as well as a peptide-specific antibody response. Thus, the nasal administration of an apoB-100 peptide fused to $\mathrm{CTB}$ attenuates atherosclerosis and induces regulatory Treg1 cells that inhibit $\mathrm{T}$ effector responses to apoB-100.

On the other hand, it has been suggested that antibodies reactive to ox-LDL may contribute to the pathogenesis of atherosclerosis [29]; however, anti-ox-LDL IgM antibodies may protect against atherosclerosis possibly because they can scavenge the ox-LDL particles [30]. Grosso et al. have reported that the passive immunization with xenogeneic polyclonal antibodies, xenogeneic Fab fragments, and allogeneic monoclonal IgG antibodies, reactive to electronegative LDL (minimally modified LDL), significantly reduced atherosclerosis in LDL-receptor-deficient mice [10].

Recombinant human antibodies against MDA-ApoB100, 2D03-IgG, were very effective in promoting atherosclerotic lesion regression in ApoB100-expressing LDL receptor deficient mice, which has been suggested to come about as a result of reduced macrophage infiltration and enhanced cholesterol efflux [21].

Finally, approaches based on evidence produced by clinical studies have revealed an inverse association between antibodies to malondialdehyde- (MDA-) modified fibronectin and a risk of cardiovascular events. The immunization of apoprotein E- (ApoE-) deficient mice with MDA-modified fibronectin resulted in a $70 \%$ decrease in plaque area and a less inflammatory phenotype of remaining plaques. Immunization converted a weak naturally occurring Th1 antibody response against MDA-fibronectin into a Th2 antibody response. Cytokine expression and flow cytometry analyses of spleen cells from immunized mice showed an activation of regulatory $\mathrm{T}$ cells. Immunization with MDAfibronectin was also found to reduce plasma fibronectin levels [13]. It is important to highlight that MDA-fibronectin represents a possible novel target for immunomodulatory therapy in atherosclerosis.

\section{Heat Shock Proteins}

Autoimmunity to heat shock proteins (HSPs) is one element in atherosclerosis-induced immune responses. HSPs are a class of functionally related, highly conserved proteins that function as sentinels in the so-called cellular stress response [31].

Repeated mucosal administration of Mycobacterium HSP60/65, both orally and nasally, inhibited atherosclerotic lesion formation in LDL-receptor-deficient mice when compared to the control group. The observed attenuation of atherosclerosis was associated with decreased macrophage and T-cell numbers and enhanced IL-10 intimal expression, but this was observed in the intranasally treated animals only [23]. Oral tolerance induction to Mycobacterium HSP60 derivatives attenuates atherosclerotic lesion formation by $80 \%$ in a model of flow-induced carotid artery atherosclerosis. The protective effect of oral HSP60 administration is due to enhanced regulatory T-cell expansion and function, rather than the induction of HSP-specific antibodies [24].

\section{B-Cell Modulation}

The development of atherosclerosis is also associated with signs of B-cell activation, particularly manifested by enhanced production of natural IgM-type and adaptive IgG-type anti-oxLDL autoantibodies [32]. Although IgGtype anti-oxLDL antibodies show variable association with vascular risk, circulating levels of IgM type anti-oxLDL antibodies have been more frequently linked with reduced vascular risk in humans [33].

B-cell activation, until now, has been associated with protection against atherosclerosis, suggesting that B-celldepleting therapies would enhance cardiovascular risk, but unexpectedly, Ait-Oufella and coworkers demonstrated that mature B-cell depletion using a CD20-specific monoclonal antibody induces a significant reduction of atherosclerosis in 
various mouse models of the disease. This treatment preserves the production of natural and potentially protective anti-oxLDL IgM autoantibodies over IgG-type anti-oxLDL antibodies and markedly reduces pathogenic $\mathrm{T}$ cell activation. B-cell depletion diminished T-cell-derived IFN- $\gamma$ secretion and enhanced production of IL-17; neutralization of the latter abrogated CD20 antibody-mediated atheroprotection. These results challenge the current paradigm that B-cell activation plays an overall protective role in atherogenesis and identify new antiatherogenic strategies based on B-cell modulation [11].

Although limited vascular B-cell infiltration is detectable in the early stages of atherosclerosis, B-cell accumulation substantially increases with time. It localizes within and around advanced atherosclerotic coronary lesions and atherosclerotic abdominal aortic aneurysms [34] of mice and humans and is even prominent in vascular inflammation associated with other immunomediated diseases [35]. Inhibition of excessive B-cell activation either through depletion or immune modulation might substantially limit vascular inflammation and atherosclerotic lesion development.

\section{Therapies Based on Response-to-Retention Hypothesis}

Although many factors, such as LDL oxidation, oxidative stress, endothelial dysfunction, and inflammation, are involved in atherogenesis, the retention of apoB-containing lipoproteins in the artery wall is critical in the initiation and progression of the disease [5]. Despite the cholesterollowering effect and anti-inflammatory properties of statins, atherosclerosis continues to progress in a significant proportion of patients, and there is no pharmaceutical treatment directly targeting the vessel wall [36]. Thus, there is widespread agreement on the need of therapies directed to avoid the retention of atherogenic lipoproteins in the artery wall, which would complement current therapies.

The aorta is an abundant tissue source of the heparan sulfate proteoglycan (PG) collagen XVIII and its proteolytically released endostatin (ES) fragment, which has previously been shown to inhibit angiogenesis in cancer and atherosclerosis models [37]. The ES portion of collagen XVIII has no attachment sites for GAG but has high affinity for heparin, which is necessary for its antiangiogenesis functions [38]. A recent data has shown that collagen XVIII is differentially degraded in blood vessels affected by atherosclerosis. Loss of collagen XVIII/ES resulted in enhanced plaque neovascularization and vascular permeability to lipids in mice prone to developing atherosclerosis [39].

In 2005 Zeng et al. [25] demonstrated a novel property of ES that binds both the matrix proteoglycan biglycan and LDL and interferes with LDL retention to biglycan and to subendothelial matrix. A peptide encompassing the coil in the ES crystal structure mediates the major blocking effect of ES on LDL retention. ES indirectly inhibits the macrophage uptake of biglycan-associated LDL by interfering with LDL retention to biglycan, but it has no direct effect on the macrophage uptake of native or modified lipoproteins. These findings suggest that ES exerts antiatherosclerotic effects mainly by interfering with LDL-PG binding.

Taking into account Williams and Tabas's retention hypothesis and the most relevant advances about the roles of GAG on atherogenesis, our group obtained a chimeric monoclonal antibody that binds sulfated molecules, such as PG-contained GAG. Our therapeutic strategy, which has not been previously explored, is the use of antibodies that through their recognition of proatherogenic GAG interfere with LDL retention and are also capable of inducing autologous antibodies with similar properties in the immunized animals, acting as idiotypic vaccines [15].

We evaluated the potential antiatherogenic effect of the antibody chP3R99 in a Lipofundin model of atherosclerosis, described previously by Jellinek et al. and recharacterized by our group $[40,41]$. Our data demonstrated that the immunization with the chP3R99 monoclonal antibody prevented the development of atherosclerosis lesions, and this effect was associated with its capacity to induce antibodies capable of blocking the binding of LDL to chondroitin sulfate (CS) and their oxidation, thus acting as an idiotypic vaccine. We also showed that its antiatherosclerotic effects are associated with the capability of preserving the aortic redox state. In addition, this study provides data strongly supporting the response-to-retention hypothesis as the key event in the initiation of atherosclerosis.

\section{Metabolic Factors: A clinical Study Using Adipose Antigens Pool}

Bourinbaiar and Jirathitikal recently published the results of a small clinical study that utilized oral immunization with pooled adipose antigens in obese subjects [42]. The pooled antigens were obtained from pig adipose tissue and were administered daily per os for three months, assessing the effect on plasma cholesterol and body weight. Whether or not this prolonged immunization protocol resulted in antibody formation to the antigens is not demonstrated in the paper. The authors do claim an effect on plasma high-density lipoprotein (HDL) levels, which increased by $25 \%$, while total cholesterol levels remained similar when compared to baseline levels. The effect on body mass index (BMI) was insignificant, though waist diameter slightly decreased.

Though the above studies are very preliminary with several aspects to be improved upon, an initial step has been taken towards the discovery of obesity- and atherosclerosisspecific antigens. The chosen targets were selected from a "metabolic" perspective but can also be employed the other way around.

\section{Conclusions}

Nowadays, many basic and clinical researchers around the world work together in delineating therapeutic targets for the immunoregulation of atherosclerosis. Novel therapeutic tools, particularly, antiatherosclerotic vaccination, are under development. Therapies based on arterial wall targets are of major importance due to the relevant role of LDL retention 
by GAGs and its oxidation by reactive oxygen species. Furthermore, additional studies of the effects of different vaccine strategies on progression of atherosclerosis are needed in order to implement the therapy in patients. Currently, most studies have focused on atherosclerotic lesion development, while lesion progression or even regression are, at this time, more clinically relevant as patients are usually only seen by the cardiologist when they have clinically manifested atherosclerosis. All of these warrant further investigation, especially in large animal models and humans.

\section{Conflict of Interests}

There are no conflicts of interests.

\section{Acknowledgment}

The author wants to thank Dr. Ana María Vázquez (Ph.D.) from the Center of Molecular Immunology, Havana, Cuba, for her useful and excellent guide.

\section{References}

[1] S. Mendis, P. Puska, and B. Norrving, Eds., Global Atlas on Cardiovascular Disease Prevention and Control, World Health Organization, Geneva, Switzerland, 2011.

[2] D. Steinberg, S. Parthasarathy, T. E. Carew, J. C. Khoo, and J. L. Witztum, "Beyond cholesterol: Modifications of low-density lipoprotein that increase its atherogenicity," The New England Journal of Medicine, vol. 320, no. 14, pp. 915-924, 1989.

[3] D. Steinberg, "Atherogenesis in perspective: Hypercholesterolemia and inflammation as partners in crime," Nature Medicine, vol. 8, no. 11, pp. 1211-1217, 2002.

[4] K. J. Williams and I. Tabas, "The response-to-retention hypothesis of early atherogenesis," Arteriosclerosis, Thrombosis, and Vascular Biology, vol. 15, pp. 551-561, 1995.

[5] I. Tabas, K. J. Williams, and J. Borén, "Subendothelial lipoprotein retention as the initiating process in atherosclerosis: update and therapeutic implications," Circulation, vol. 116, no. 16, pp. 1832-1844, 2007.

[6] G. K. Hansson, "Immune and inflammatory mechanisms in the development of atherosclerosis," British Heart Journal, vol. 69, no. 1, pp. S38-S41, 1993.

[7] R. Ross, "Atherosclerosis - an inflammatory disease," The New England Journal of Medicine, vol. 340, no. 2, pp. 115-126, 1999.

[8] P. K. Shah, "Apolipoprotein A-I/HDL infusion therapy for plaque stabilization-regression: a novel therapeutic approach," Current Pharmaceutical Design, vol. 13, no. 10, pp. 1031-1038, 2007.

[9] C. Kishimoto, "Immunoglobulin therapy, myocardial diseases and atherosclerosis: recent experimental and clinical studies," Current Cardiology Reviews, vol. 3, no. 1, pp. 15-21, 2007.

[10] D. M. Grosso, S. Ferderbar, A. C. B. A. Wanschel, M. H. Krieger, M. L. Higushi, and D. S. P. Abdalla, "Antibodies against electronegative LDL inhibit atherosclerosis in LDLr-/mice," Brazilian Journal of Medical and Biological Research, vol. 41, no. 12, pp. 1086-1092, 2008.

[11] H. Ait-Oufella, O. Herbin, J. D. Bouaziz et al., "B cell depletion reduces the development of atherosclerosis in mice," Journal of Experimental Medicine, vol. 207, no. 8, pp. 1579-1587, 2010.
[12] K. L. L. Habets, G. H. M. Van Puijvelde, L. M. Van Duivenvoorde et al., "Vaccination using oxidized low-density lipoprotein-pulsed dendritic cells reduces atherosclerosis in LDL receptor-deficient mice," Cardiovascular Research, vol. 85, no. 3, pp. 622-630, 2010.

[13] P. Dunér, F. To, K. Beckmann et al., "Immunization of apoE-/- mice with aldehyde-modified fibronectin inhibits the development of atherosclerosis," Cardiovascular Research, vol. 91, no. 3, pp. 528-536, 2011.

[14] A. Hermansson, D. K. Johansson, D. F. J. Ketelhuth, J. Andersson, X. Zhou, and G. K. Hansson, "Immunotherapy with tolerogenic apolipoprotein B-100-loaded dendritic cells attenuates atherosclerosis in hypercholesterolemic mice," Circulation, vol. 123, no. 10, pp. 1083-1091, 2011.

[15] Y. Soto, E. Acosta, L. Delgado et al., "Antiatherosclerotic effect of an antibody that binds to extracellular matrix glycosaminoglycans," Arteriosclerosis, Thrombosis, and Vascular Biology, vol. 32, pp. 595-604, 2012.

[16] M. H. Davidson, K. Maki, D. Umporowicz, A. Wheeler, C. Rittershaus, and U. Ryan, "The safety and immunogenicity of a CETP vaccine in healthy adults," Atherosclerosis, vol. 169, no. 1, pp. 113-120, 2003.

[17] S. Amir and C. J. Binder, "Experimental immunotherapeutic approaches for atherosclerosis," Clinical Immunology, vol. 134, no. 1, pp. 66-79, 2010.

[18] Y. J. Geng and L. Jonasson, "Linking immunity to atherosclerosis: implications for vascular pharmacology -A tribute to Göran K. Hansson," Vascular Pharmacology, vol. 56, pp. 2933, 2012.

[19] C. W. Rittershaus, D. P. Miller, L. J. Thomas et al., "Vaccineinduced antibodies inhibit CETP activity in vivo and reduce aortic lesions in a rabbit model of atherosclerosis," Arteriosclerosis, Thrombosis, and Vascular Biology, vol. 20, no. 9, pp. 2106-2112, 2000.

[20] Q. Gaofu, L. Jun, Y. Xin et al., "Vaccinating rabbits with a cholesteryl ester transfer protein (CETP) B-cell epitope carried by heat shock protein-65 (HSP65) for inducing anti-CETP antibodies and reducing aortic lesions in vivo," Journal of Cardiovascular Pharmacology, vol. 45, no. 6, pp. 591-598, 2005.

[21] A. Schiopu, B. Frendéus, B. Jansson et al., "Recombinant antibodies to an oxidized low-density lipoprotein epitope induce rapid regression of atherosclerosis in apobec-1-/-/low-density lipoprotein receptor-/- mice," Journal of the American College of Cardiology, vol. 50, no. 24, pp. 2313-2318, 2007.

[22] R. Klingenberg, M. Lebens, A. Hermansson et al., "Intranasal immunization with an apolipoprotein B-100 fusion protein induces antigen-specific regulatory $\mathrm{T}$ cells and reduces atherosclerosis," Arteriosclerosis, Thrombosis, and Vascular Biology, vol. 30, no. 5, pp. 946-952, 2010.

[23] R. Maron, G. Sukhova, A. M. Faria et al., "Mucosal administration of heat shock protein-65 decreases atherosclerosis and inflammation in aortic arch of low-density lipoprotein receptor-deficient mice," Circulation, vol. 106, no. 13, pp. 1708-1715, 2002.

[24] G. H. M. Van Puijvelde, T. Van Es, E. J. A. Van Wanrooij et al., "Induction of oral tolerance to HSP60 or an HSP60peptide activates t cell regulation and reduces atherosclerosis," Arteriosclerosis, Thrombosis, and Vascular Biology, vol. 27, no. 12 , pp. 2677-2683, 2007.

[25] X. Zeng, J. Chen, Y. I. Miller, K. Javaherian, and K. S. Moulton, "Endostatin binds biglycan and LDL and interferes with LDL retention to the subendothelial matrix during atherosclerosis," Journal of Lipid Research, vol. 46, no. 9, pp. 1849-1859, 2005. 
[26] D. Mao, G. Kai, Q. Gaofu et al., "Intramuscular immunization with a DNA vaccine encoding a 26-amino acid CETP epitope displayed by $\mathrm{HBc}$ protein and containing CpG DNA inhibits atherosclerosis in a rabbit model of atherosclerosis," Vaccine, vol. 24, no. 23, pp. 4942-4950, 2006.

[27] G. Qi, J. Li, S. Wang et al., "A chimeric peptide of intestinal trefoil factor containing cholesteryl ester transfer protein B cell epitope significantly inhibits atherosclerosis in rabbits after oral administration," Peptides, vol. 32, no. 4, pp. 790-796, 2011.

[28] G. N. Fredrikson, I. Söderberg, M. Lindholm et al., "Inhibition of atherosclerosis in apoE-null mice by immunization with apoB-100 peptide sequences," Arteriosclerosis, Thrombosis, and Vascular Biology, vol. 23, no. 5, pp. 879-884, 2003.

[29] W. Palinski and J. L. Witztum, "Immune responses to oxidative neoepitopes on LDL and phospholipids modulate the development of atherosclerosis," Journal of Internal Medicine, vol. 247, no. 3, pp. 371-380, 2000.

[30] P. X. Shaw, S. Hörkkö, S. Tsimikas et al., "Human-derived antioxidized LDL autoantibody blocks uptake of oxidized LDL by macrophages and localizes to atherosclerotic lesions in vivo," Arteriosclerosis, Thrombosis, and Vascular Biology, vol. 21, no. 8, pp. 1333-1339, 2001.

[31] A. De Maio, "Heat shock proteins: facts, thoughts, and dreams," Shock, vol. 11, no. 1, pp. 1-12, 1999.

[32] G. Caligiuri, A. Nicoletti, B. Poirierand, and G. K. Hansson, "Protective immunity against atherosclerosis carried by B cells of hypercholesterolemic mice," Journal of Clinical Investigation, vol. 109, no. 6, pp. 745-753, 2002.

[33] S. Tsimikas, E. S. Brilakis, R. J. Lennon et al., "Relationship of IgG and IgM autoantibodies to oxidized low density lipoprotein with coronary artery disease and cardiovascular events," Journal of Lipid Research, vol. 48, no. 2, pp. 425-433, 2007.

[34] M. P. W. Moos, N. John, R. Gräbner et al., "The lamina adventitia is the major site of immune cell accumulation in standard chow-fed apolipoprotein E-deficient mice," Arteriosclerosis, Thrombosis, and Vascular Biology, vol. 25, no. 11, pp. 23862391, 2005.

[35] M. C. Aubry, D. L. Riehle, W. D. Edwards et al., "B-Lymphocytes in plaque and adventitia of coronary arteries in two patients with rheumatoid arthritis and coronary atherosclerosis: preliminary observations," Cardiovascular Pathology, vol. 13, no. 4, pp. 233-236, 2004.

[36] P. J. Little, M. L. Ballinger, and N. Osman, "Vascular wall proteoglycan synthesis and structure as a target for the prevention of atherosclerosis," Vascular Health and Risk Management, vol. 3, no. 1, pp. 117-124, 2007.

[37] W. Halfter, S. Dong, B. Schurer, and G. J. Cole, "Collagen XVIII is a basement membrane heparan sulfate proteoglycan," Journal of Biological Chemistry, vol. 273, no. 39, pp. 2540425412, 1998.

[38] S. Dong, G. J. Cole, and W. Halfter, "Expression of collagen XVIII and localization of its glycosaminoglycan attachment sites," Journal of Biological Chemistry, vol. 278, no. 3, pp. 17001707, 2003.

[39] K. S. Moulton, B. R. Olsen, S. Sonn, N. Fukai, D. Zurakowski, and X. Zeng, "Loss of collagen XVIII enhances neovascularization and vascular permeability in atherosclerosis," Circulation, vol. 110, no. 10, pp. 1330-1336, 2004.

[40] L. D. Roche, E. A. Medina, Y. Hernández-Matos, M. A. Bécquer Viart, A. M. Vázquez López, and E. FernándezSánchez, "High levels of lipid peroxidation induced by
Lipofundin administration correlate with atherosclerotic lesions in rabbits," Pharmacologyonline, vol. 3, pp. 727-736, 2010.

[41] L. Delgado, E. Acosta, A. Fraga et al., "Lipofundin-induced hyperlipidemia promotes oxidative stress and atherosclerotic lesions in New Zealand white rabbits," International Journal of Vascular Medicine, vol. 2012, pp. 1-7, 2011.

[42] A. S. Bourinbaiar and V. Jirathitikal, "Effect of oral immunization with pooled antigens derived from adipose tissue on atherosclerosis and obesity indices," Vaccine, vol. 28, no. 15, pp. 2763-2768, 2010. 


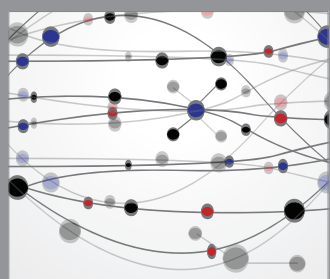

The Scientific World Journal
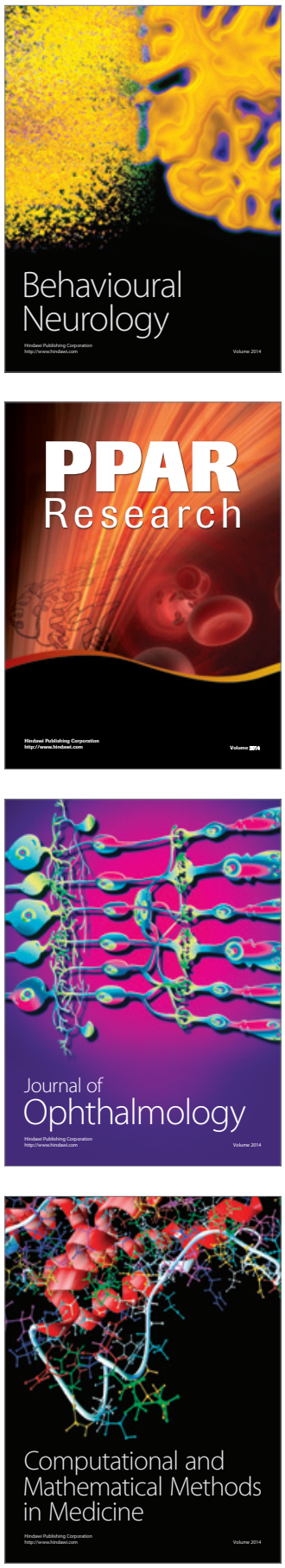

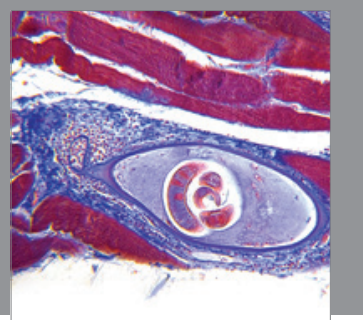

Gastroenterology

Research and Practice
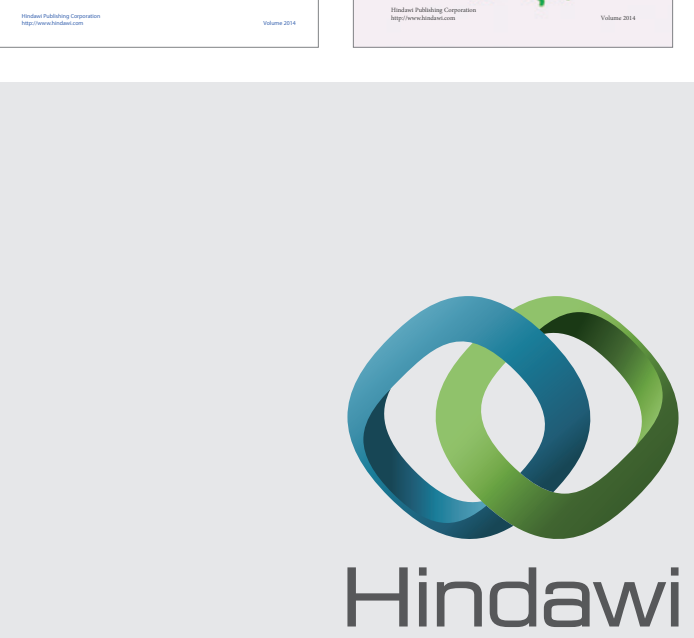

Submit your manuscripts at

http://www.hindawi.com
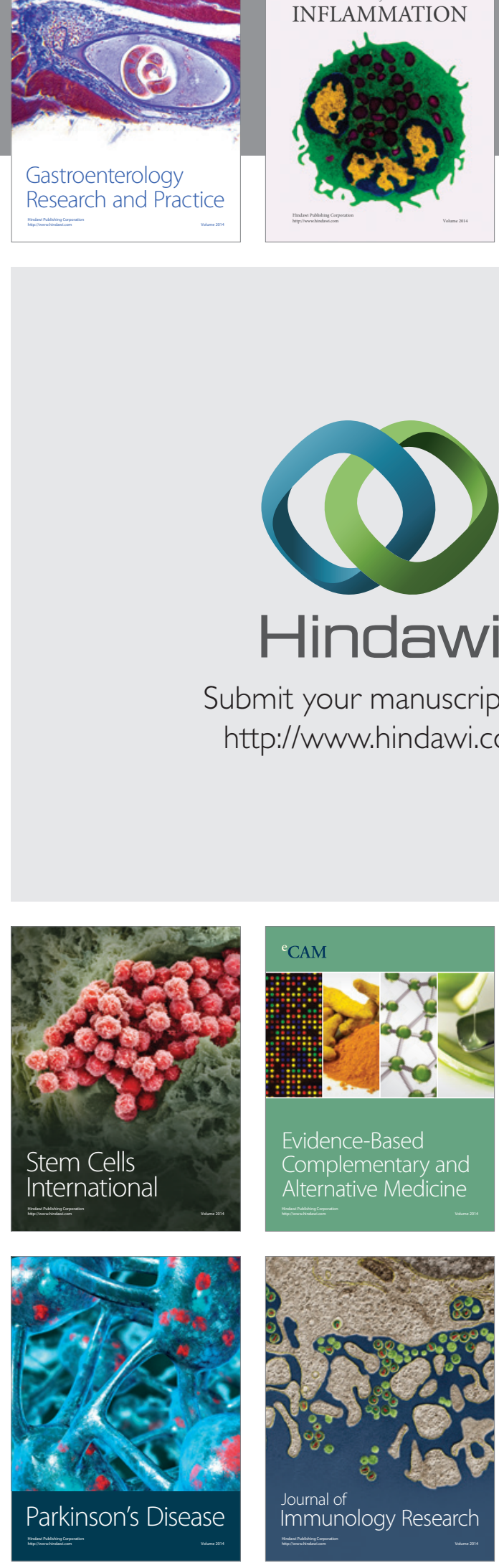

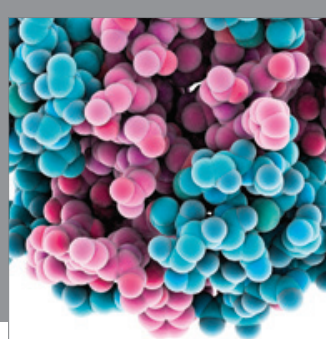

Diabetes Research
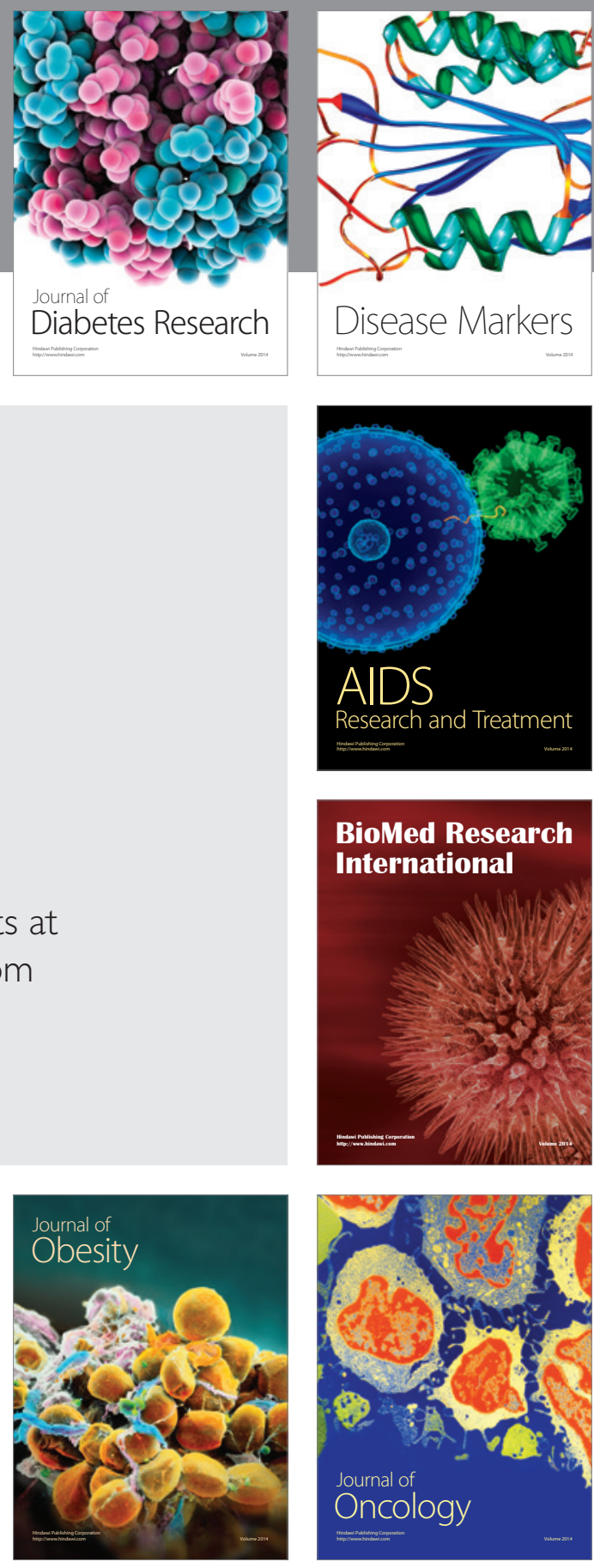

Disease Markers

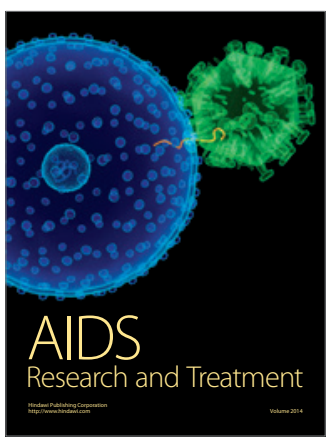

BioMed Research

International
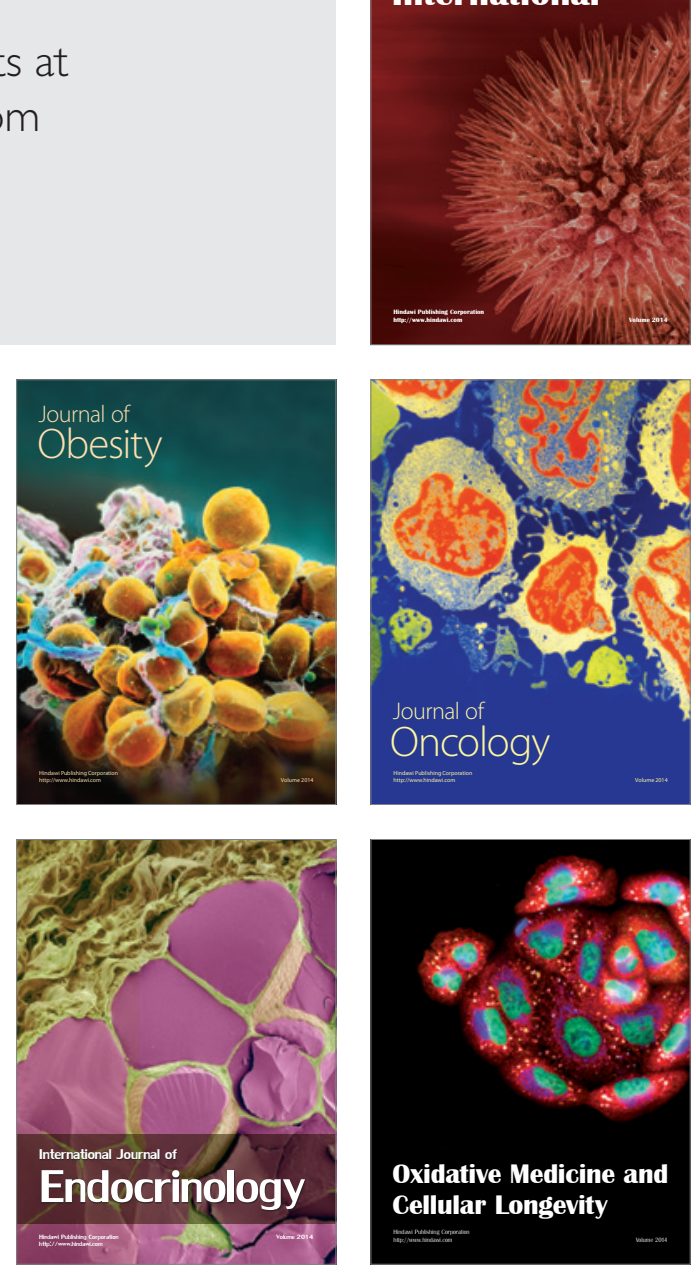